\title{
Parameter Optimisation in Vibration Assisted Turning of Ti6Al4V Alloy using ANOVA and Grey Relational Analysis
}

\author{
D. Venkata Sivareddy*, P. Vamsi Krishna, A. Venu Gopal and C. L. Prithvi Raz \\ Department of Mechanical Engineering, National Institute of Technology Warangal, \\ Telangana, India-504006 \\ "Email: dvsivareddy2006@gmail.com \\ Phone: +919494510199
}

\begin{abstract}
The machining of Ti6Al4V alloy with vibration assisted turning (VAT) is an effective consideration to control the surface integrity of machined components. The effect of cutting and vibrating parameters in a VAT on cutting force, cutting temperature, equivalent stress and compressive maximum circumferential residual stress (MCRS) was studied in the present work. The parameter optimisation of a VAT of Ti6Al4V alloy was achieved with Taguchi based analysis of variance (ANOVA) and grey relational analysis (GRA). The input parameters considered for optimisation of VAT process are cutting speed, feed rate, frequency and amplitude. The finite element (FE) simulations were performed with commercial FE code, ABAQUS. The result shows that the vibrating parameters (frequency and amplitude) play a significant role than cutting parameters (speed and feed rate) in VAT process. The optimum condition for each output response was determined from ANOVA. The optimum condition obtained at $30 \mathrm{~m} / \mathrm{min}$ of cutting speed, $150 \mu \mathrm{m}$ of amplitude, $600 \mathrm{~Hz}$ of frequency and $0.05 \mathrm{~mm} / \mathrm{rev}$ of feed rate for cutting force, cutting temperature and MCRS (compressive) while the optimum condition for equivalent stress is $30 \mathrm{~m} / \mathrm{min}$ of cutting speed, $100 \mu \mathrm{m}$ of amplitude, $600 \mathrm{~Hz}$ of frequency and $0.05 \mathrm{~mm} / \mathrm{rev}$ of feed rate. The GRA suggests the combination of process parameters $30 \mathrm{~m} / \mathrm{min}$ of cutting speed, $150 \mu \mathrm{m}$ of amplitude, $600 \mathrm{~Hz}$ of frequency and $0.05 \mathrm{~mm} / \mathrm{rev}$ of feed rate provides the optimum response.
\end{abstract}

Keywords: Vibration-assisted turning; Ti6Al4V alloy; finite element simulation; ANOVA; GRA; optimisation.

\section{INTRODUCTION}

Precision machining of new alloys and composite materials used in aerospace, defence, biomedical and automotive industry is a challenge to researchers. Dimensional inaccuracy and poor surface quality are the major problems in machining of hard materials like titanium alloys due to their high chemical affinity, high toughness and low thermal conductivity. Conventional machining of titanium alloys generates high cutting temperatures and large cutting forces resulting in rapid tool wear and generation of residual stresses, even at low cutting speeds $[1,2]$. These problems lead to lack of dimensional accuracy and poor surface quality. To overcome these problems, an innovative machining technique vibration assisted turning (VAT) was developed $[1,2]$. VAT is an advanced machining process in which high frequency and small amplitude are led to impose on cutting tool to get the intermittent cutting unlike continuous cutting in conventional turning (CT) in machining difficult to cut material [3-5]. 
Mitrofanov et al. [6] studied the effect of cutting parameters such as cutting speed, depth of cut and feed rate on cutting force, cutting temperature and chip formation. A decrease in the feed rate reduced a considerable amount of cutting force and cutting temperature in the machining zone. Ahmed et al. [7] studied the effect of feed rate, friction, frequency and amplitude on cutting force in a VAT. An increase in vibrating frequency and amplitude decreased a large amount of cutting forces in VAT resulting in improved cutting accuracy and material removal rate. They also reported that vibration in tangential direction reduced more force than vibration in the feed direction. In another attempt, Chandra Nath et al. [8] found that cutting force, tool wear and surface roughness are very less in the VAT process than CT. They found that cutting quality in a VAT was improved with higher amplitude and frequency and low cutting speed due to reduced tool work contact. Amini et al. [9] studied the effect of tool geometry, cutting speed and ultrasonic vibration amplitude on forces and stresses in a VAT. They observed that cutting forces and stresses are significantly less in VAT compared to CT. They also found that cutting force is increased with cutting speed and reduced with rake angle, whereas the clearance angle did not influence the cutting force. In another study, Ahmed Syed et al. [10] studied the effect of transverse vibration on the movement of the cutting tool. They found that cutting force and thrust force in VAT were decreased with an increase in amplitude. But the surface finish was decreased with the increase in amplitude in transverse vibration. Babitsky et al. [11] found that surface finish improvement in a VAT was more when vibrations applied in cutting direction, whereas scattering type surface found in a machined component in transverse vibration.

The stresses induced during machining process remain in machined component after machining is known as residual stresses. The thermo-mechanical phenomenon in machining process causes generation of residual stresses. These stresses may be compressive or tensile. The increased temperature in the cutting zone is responsible for tensile stresses whereas mechanical loading by the cutting tool on the workpiece is responsible for compressive residual stresses. The fatigue life of the machined component reduced by initiating crack propagation due to tensile stresses when subjected to different loading whereas compressive residual stresses help to improve fatigue life and corrosion resistance [12]. Few researchers worked to optimise the machining parameters for generation of compressive residual stresses [13, 14]. Fu et al. [15] investigated the effect of tool geometry and depth of cut on residual stresses. They observed that compressive residual stresses developed with an increase in rake angle and nose radius. In another attempt, Capello et al. [16] studied the effect of nose radius and feed rate on residual stresses in turning by developing the empirical methodology. Contradictory to Capello, Rech et al. [17] found that the depth of cut and cutting speed are the most significant parameters than feed rate in the generation of residual stresses. Ulutan et al. [18] developed an empirical model to study the generation of residual stresses, and thermomechanical model is used to study temperature profile in the machining zone. Saini et al. [19] studied the effect of cutting parameters on residual stresses. They found that circumferential residual stresses are affected by feed rate whereas tangential residual stresses are affected by the depth of cut. Naresh et al. [20] studied the effect of workpiece hardness on residual stresses and also discussed the variation of residual stresses in the machined component from tensile to compressive with an increase in the depth direction. Ozel et al. [21] observed that tool geometry played an important role in the generation of residual stresses in conventional machining of Ni-based alloys.

From the literature, there is no unique agreement between researchers concerning the effect of cutting parameters on the generation of residual stresses. Very few works 
have discussed the optimisation of machining parameters for minimum residual stress generation in VAT process. In this study an attempt has been made to optimise the machining and vibration parameters for reducing cutting forces, cutting temperature and residual stresses. Taguchi experimental design was used for experimental design during VAT of Ti6Al4V alloy. The results are analysed with Analysis of Variance (ANOVA) and Grey Relational Analysis (GRA) to achieve the optimum machining condition. ANOVA is applied to know the most influencing input parameter on output responses [22]. GRA is employed to combine all output responses into one grade and determine the optimised condition for machining. Confirmation tests were performed by using the FE model.

\section{EXPERIMENTAL DESIGN}

Taguchi parameter design is an important statistical tool which uses orthogonal arrays to analyse the machining parameters with a smaller number of experiments. The factors and levels selected for this study are listed in Table 1 . The levels of parameters are selected to cover a wide range of machining conditions [23-27]. The selected parameters are cutting speed and feed rate, vibration frequency and amplitude had no interaction among them and considered as independent parameters [23]. The response variables chosen for this study are an average cutting force, average cutting temperature and maximum effective stress (Equivalent stress) and compressive maximum circumferential residual stress (MCRS). According to Stephanie Fraley et al. [28], Taguchi $\mathrm{L}_{27}\left(3^{4}\right)$ array with four control parameters with three levels was used in the design of experiment for simulation (Table. 2).

Table 1. Machining parameters and their levels for simulation with Ti6Al4V alloy

\begin{tabular}{lccc}
\hline Parameters & Level 1 & Level 2 & Level 3 \\
\hline Cutting speed, A $(\mathrm{m} / \mathrm{min})$ & 30 & 45 & 60 \\
Amplitude, B $(\mu \mathrm{m})$ & 50 & 100 & 150 \\
Frequency, C $(\mathrm{Hz})$ & 200 & 400 & 600 \\
Feed rate, D $(\mathrm{mm} / \mathrm{rev})$ & 0.05 & 0.1 & 0.15 \\
\hline
\end{tabular}

\section{FINITE ELEMENT MODELING}

\section{FE Model Description}

The 3D FE model has many advantages over the 2D model which generates more reliable data as it resembles the actual machining. In this study, an FE model of 3D orthogonal turning is developed in ABAQUS to simulate the CT and VAT process of Titanium alloy, Ti6Al4V using Tungsten carbide as a cutting tool as shown in Figure 1. The cutting tool was assumed as a rigid body to reduce the simulation time. The workpiece material Ti6Al4V was modelled as plastically deformable material subjected to a high strain rate of $2000 \mathrm{~s}^{-1}$. The details of the machining conditions are listed in Table 3.

\section{Element type}

An eight-node temperature-displacement coupled trilinear brick element, C3D8RT in ABAQUS was used for mechanical and thermal analysis with reduced integration and 
hourglass control. Using reduced integration and hourglass control can remove shear and volumetric locking effects and also, reduces the running time especially in 3D. The workpiece was meshed with 124000 elements with element deletion. The total machining time in the simulation is $0.01 \mathrm{sec}$ which includes 200 cycles at a frequency of $20 \mathrm{kHz}$.

Table 2: Taguchi $\mathrm{L}_{27}$ orthogonal array

\begin{tabular}{ccccc}
\hline Trial No. & $\begin{array}{c}\text { Cutting speed } \\
(\mathrm{m} / \mathrm{min})\end{array}$ & $\begin{array}{c}\text { Amplitude } \\
(\mu \mathrm{m})\end{array}$ & $\begin{array}{c}\text { Frequency } \\
(\mathrm{Hz})\end{array}$ & $\begin{array}{c}\text { Feed rate } \\
(\mathrm{mm} / \mathrm{rev})\end{array}$ \\
\hline 1 & 30 & 50 & 200 & 0.05 \\
2 & 30 & 50 & 400 & 0.1 \\
3 & 30 & 50 & 600 & 0.15 \\
4 & 30 & 100 & 200 & 0.1 \\
5 & 30 & 100 & 400 & 0.15 \\
6 & 30 & 100 & 600 & 0.05 \\
7 & 30 & 150 & 200 & 0.15 \\
8 & 30 & 150 & 400 & 0.05 \\
9 & 30 & 150 & 600 & 0.1 \\
10 & 45 & 50 & 200 & 0.1 \\
11 & 45 & 50 & 400 & 0.15 \\
12 & 45 & 50 & 600 & 0.05 \\
13 & 45 & 100 & 200 & 0.15 \\
14 & 45 & 100 & 400 & 0.05 \\
15 & 45 & 100 & 600 & 0.1 \\
16 & 45 & 150 & 200 & 0.05 \\
17 & 45 & 150 & 400 & 0.1 \\
18 & 45 & 150 & 600 & 0.15 \\
19 & 60 & 50 & 200 & 0.15 \\
20 & 60 & 50 & 400 & 0.05 \\
21 & 60 & 50 & 600 & 0.1 \\
22 & 60 & 100 & 200 & 0.05 \\
23 & 60 & 100 & 400 & 0.1 \\
24 & 60 & 100 & 600 & 0.15 \\
25 & 60 & 150 & 200 & 0.1 \\
26 & 60 & 150 & 400 & 0.15 \\
27 & 60 & 150 & 600 & 0.05 \\
\hline
\end{tabular}

\section{Johnson Cook (JC) Material Model}

The JC material model is widely used in all available FE simulation software as the results obtained are in close agreement with experimental values. This JC model represented in Eq. (1) relates the plastic flow stress as a function of strain hardening, strain rate and thermal softening [29-31].

$$
\sigma_{\mathrm{f}}=\left[\mathrm{A}+\mathrm{B}(\varepsilon)^{\mathrm{n}}\right]\left[1+\mathrm{C} \ln \left(\frac{\varepsilon^{\mathrm{o}}}{\varepsilon_{0}^{\mathrm{o}}}\right)\right]\left[1-\left(\frac{\mathrm{T}-\mathrm{T}_{\text {room }}}{\mathrm{T}_{\text {melt }}-\mathrm{T}_{\text {room }}}\right)^{\mathrm{m}}\right]
$$

where $\sigma_{\mathrm{f}}$ is the equivalent plastic flow stress; $\varepsilon$ is an equivalent plastic strain; $\varepsilon^{\mathrm{o}} / \varepsilon^{\mathrm{o}}{ }_{0}$ is the reference strain rate; $\mathrm{T}_{\text {room }}$ is the room temperature of $25{ }^{\circ} \mathrm{C} ; \mathrm{T}_{\text {melt }}$ is the melting 
temperature. $\mathrm{A}, \mathrm{B}, \mathrm{C}, \mathrm{n}$ and $\mathrm{m}$ are material constants. Material properties and JC parameters used in the present work, for the machining process are listed in Table 4 [30].

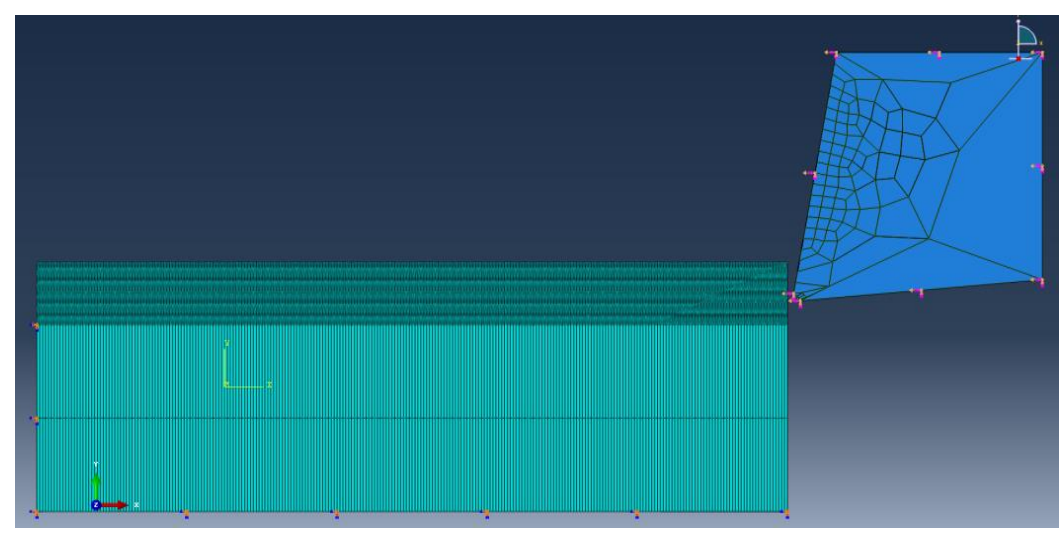

Figure 1. Workpiece and tool contact in FE modelling of the machining process.

Table 3. FE modelling parameters used in the simulation.

\begin{tabular}{|c|c|}
\hline Materials & $\begin{array}{ll}\text { Cutting tool } & \text { : tungsten carbide } \\
\text { Work piece } & : \text { titanium alloy, Ti6Al4V }\end{array}$ \\
\hline Dimension & $\begin{array}{ll}\text { Workpiece } & : 1.2 \times 0.4 \times 0.2 \mathrm{~mm} \\
\text { Cutting tool } & : 0.4 \times 0.4 \times 0.4 \mathrm{~mm} \\
\end{array}$ \\
\hline $\begin{array}{l}\text { Machining } \\
\text { conditions }\end{array}$ & $\begin{array}{ll}\text { Speed } & : 50 \mathrm{~m} / \mathrm{min} \\
\text { Depth of cut } & : 0.1 \mathrm{~mm} \\
\text { Feed rate } & : 1.03 \mathrm{~mm} / \mathrm{rev} \\
\text { Tool geometry: } & \text { rake angle, } \gamma=10^{\circ}, \text { clearance angle, } \alpha=5^{\circ}, \\
& \text { nose radius }=10 \mu \mathrm{m}\end{array}$ \\
\hline $\begin{array}{l}\text { Simulation } \\
\text { parameters }\end{array}$ & $\begin{array}{l}\text { Solver : dynamic explicit-temperature- displacement } \\
\text { Geometric order: linear } \\
\text { Element deletion: yes } \\
\text { Element distortion control: length ratio } 0.1 \\
\text { Interaction } \quad \text { : general contact, tangential behavior, penalty contact } \\
\quad \text { friction coefficient } \mu=0.6\end{array}$ \\
\hline
\end{tabular}

\section{Criteria for Chip Separation}

Different strategies have been used to accurate prediction of material flow distribution in the modelling of the material machining process. JC failure model is one among those used to simulate the chip separation in machining process efficiently. According to this model, the expression for the damage parameter D is given by Eq. (2) [29, 31].

$$
\mathrm{D}=\sum\left(\frac{\Delta \epsilon_{\mathrm{p}}}{\epsilon_{\mathrm{f}}}\right)
$$

where $\Delta \epsilon_{\mathrm{p}}$ the increment of equivalent plastic strain which is updated at every analysis increment; $\epsilon_{\mathrm{f}}$ is an equivalent plastic strain in damaged element and it is expressed as a function of stress triaxiality p/q (ratio of hydrostatic to Von Mises stresses), strain rate $\epsilon_{\mathrm{P}}$ and temperature $\mathrm{T}$ as given by Eq. (3). 


$$
\epsilon_{\mathrm{f}}=\left[\mathrm{D}_{1}+\mathrm{D}_{2} \exp \left(\mathrm{D}_{3} \frac{\mathrm{p}}{\mathrm{q}}\right)\right]\left[1+\mathrm{D}_{4} \ln \left(\frac{\epsilon_{\mathrm{P}}}{\epsilon}\right)\right]\left[1+\mathrm{D}_{5}\left(\frac{\mathrm{T}-\mathrm{T}_{\text {room }}}{\mathrm{T}_{\text {melt }}-\mathrm{T}_{\text {room }}}\right)\right]
$$

where $\mathrm{D}_{\mathrm{i}}(\mathrm{i}=1,2,3,4,5)$ are $\mathrm{JC}$ material damage coefficients and its corresponding values of Ti6Al4V alloy are given in Table 5.

Table 4. Material modelling and JC model parameters used in the simulation model.

\begin{tabular}{cll}
\hline & Density & $4420 \mathrm{~kg} / \mathrm{m}^{3}$ \\
& Young's modulus & $114 \mathrm{GPa}$ \\
Material & Conductivity & $7.264 \mathrm{~W} / \mathrm{m}^{\circ} \mathrm{C}$ \\
properties & Inelastic heat fraction & 0.9 \\
& Melting temperature & $1650{ }^{\circ} \mathrm{C}$ \\
& Specific heat & $526 \mathrm{~kJ} / \mathrm{kg}^{\circ} \mathrm{C}$ \\
& Strain rate & $2000 \mathrm{~s}^{-1}$ \\
\hline & Initial yield stress, A & $724.7(\mathrm{MPa})$ \\
& Hardening modulus, B & $683.1(\mathrm{MPa})$ \\
JC parameters & Work hardening exponent, $\mathrm{n}$ & 0.47 \\
& Strain rate dependency coefficient, C & $0.035(\mathrm{MPa})$ \\
& Thermal softening coefficient, m & 1 \\
\hline
\end{tabular}

Table 5. JC Damage coefficients for Ti6Al4V.

\begin{tabular}{lc}
\hline JC damage coefficients & Value \\
\hline Initial failure strain, D1 & -0.09 \\
Exponent factor, D2 & 0.25 \\
Triaxiality factor, D3 & -0.5 \\
Strain rate factor, D4 & 0.014 \\
Temperature factor, D5 & 3.87 \\
\hline
\end{tabular}

\section{Model Validation}

Cutting force, cutting temperature and stresses obtained in the simulation are validated with experimental results from literature in order to ensure the accuracy of the developed model [20]. Table 6 shows the comparison between the simulation and experimental results. The equivalent stresses, cutting forces and temperature generated in simulations shown in Figure 2 and 3 are in close agreement with literature for both VAT and CT. Variation in cutting force and cutting temperature are 3.2 and $8.04 \%$ respectively in case of CT compared to experimental results, whereas the same results were $7.2 \%$ for force and $3.1 \%$ for temperature respectively in case of the VAT. Variation in equivalent stress is observed to be $3.9 \%$ for CT and $5.9 \%$ for VAT, which is less than $10 \%$ in all cases. It was observed that the results obtained in the present model are close to the experimental results. 
Table 6. Comparison of results from simulation and experimentation for CT and VAT.

\begin{tabular}{clccc}
\hline Process & \multicolumn{1}{c}{ Comparison } & $\begin{array}{c}\text { Stress } \\
(\mathrm{MPa})\end{array}$ & Force $(\mathrm{N})$ & $\begin{array}{c}\text { Temperature } \\
\left({ }^{\circ} \mathrm{C}\right)\end{array}$ \\
\hline \multirow{3}{*}{$\mathrm{CT}$} & Experiment: previous work & - & 153 & 410 \\
& 2D simulation: previous work & 1340 & 160 & 420 \\
& 3D simulation: present work & 1392 & 158 & 443 \\
& Experiment: previous work & - & 110 & 330 \\
\multirow{3}{*}{ HVAT } & 2D simulation: previous work & 1360 & 140 & 265 \\
& 3D simulation: present work & 1279 & 102 & 340 \\
\hline
\end{tabular}

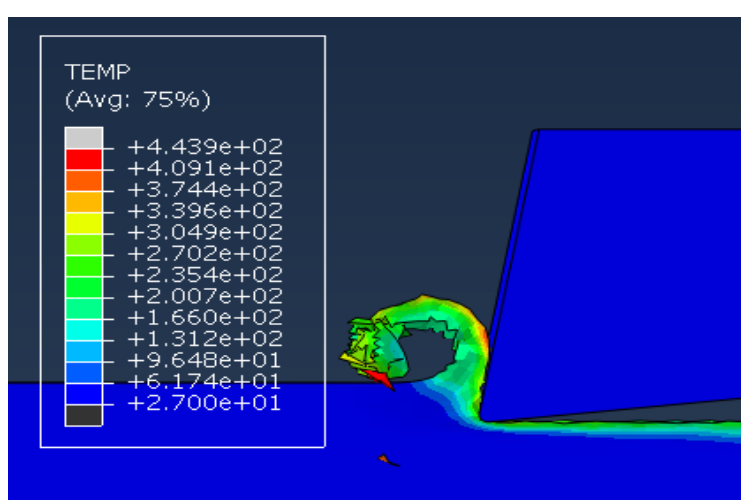

(a) CT

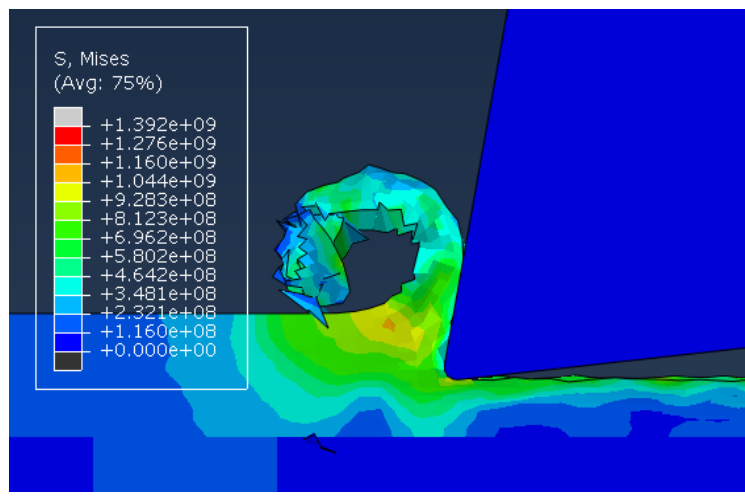

(c) $\mathrm{CT}$

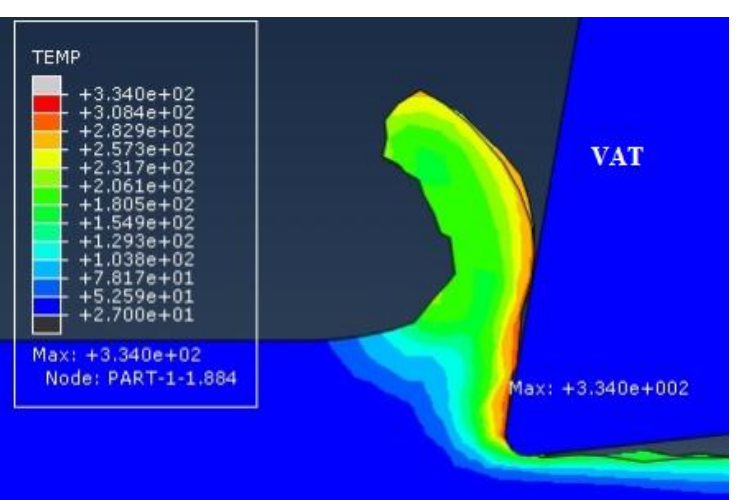

(b) VAT

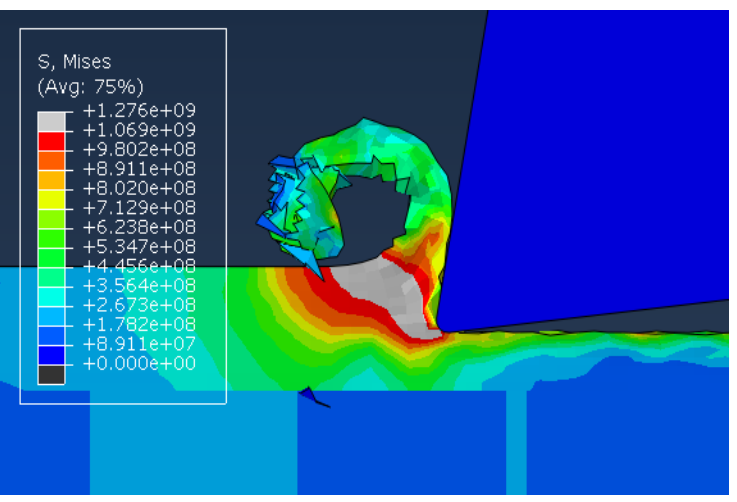

(d) VAT

Figure 2. Comparison of (a), (b) cutting temperature and; (c), (d) equivalent stress in CT and VAT. 


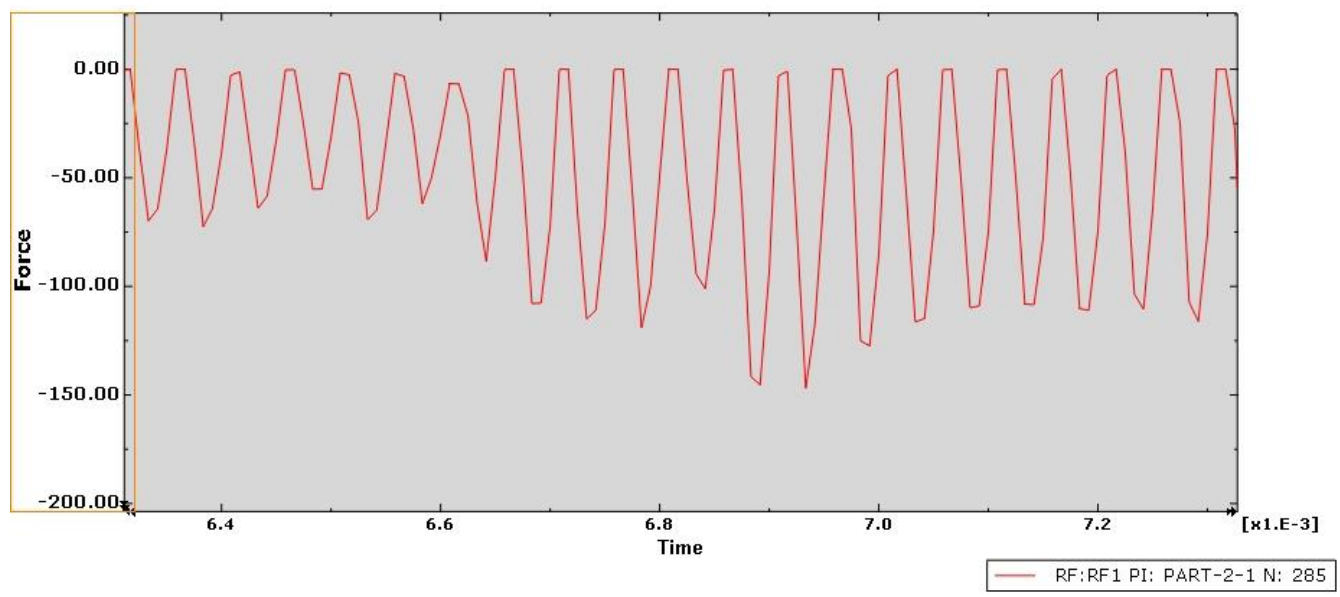

Figure 3. Variation of cutting force in VAT.

\section{RESULTS AND DISCUSSION}

FE model was developed and simulated to investigate the parameters such as cutting speed, feed rate, frequency and amplitude on equivalent stress, cutting force, cutting temperature and MCRS in VAT of Ti6Al4V alloy. Table 7 shows the simulation results of 27 trails from $\mathrm{L}_{27}$ array.

\section{Analysis of Process Parameters}

The influence of input parameters on output parameters has been evaluated using the signal to noise ratio (SNR) response analysis. The response analysis data consists of SNR, delta, rank and optimum level. The output responses were considered as important characteristics with the concept of smaller-the-better for cutting force, cutting temperature and equivalent stress and larger-the-better for MCRS (compressive). The mean SNR for each factor at each level is calculated and presented in the Tables 8, 10, 12 and 14. Delta for each factor is calculated as the difference between the highest and lowest mean SNR amongst all levels. Rank is given according to ascending order of delta value. The higher delta value for each factor is the most influence in the process.

In order to observe the practical (\%contribution $\geq 10)$ and statistical significance $(\mathrm{p} \leq 0.05)$ of machining parameters on output parameters cutting force, cutting temperature, equivalent stress and MCRS, ANOVA is performed at $95 \%$ confidence level. Normally, the larger value of $F$ and $P$ factor indicates the more effective on output variables. The other performance indicators considered in this analysis are a degree of freedom (DoF), treatment sum of squares (SSTR), and treatment mean squares (MSTR).

\section{Effect of parameters on cutting force}

The results of response data for SNR and ANOVA for cutting force are presented in Table 8 and 9 respectively. It is evident (Table 9) that the effect of frequency on cutting force is more significant while the effect of cutting speed and amplitude are moderately significant on cutting force. Figure 4 shows the variation of cutting force with cutting speed, feed rate, amplitude and frequency. The cutting force is increased by cutting speed and feed rate whereas it is decreased with increase in amplitude and frequency due to the separation between tool and workpiece per vibrating cycle. 
Table 7. Simulation results for output responses at various machining conditions.

\begin{tabular}{ccccccccc}
\hline $\begin{array}{c}\text { Trial } \\
\text { no. }\end{array}$ & $\begin{array}{c}\text { Speed } \\
(\mathrm{m} / \mathrm{min})\end{array}$ & $\begin{array}{c}\text { Amplitude } \\
(\mu \mathrm{m})\end{array}$ & $\begin{array}{c}\text { Frequency } \\
(\mathrm{Hz})\end{array}$ & $\begin{array}{c}\text { Feed } \\
(\mathrm{mm} / \mathrm{rev})\end{array}$ & $\begin{array}{c}\mathrm{F}_{\mathrm{c}} \\
(\mathrm{N})\end{array}$ & $\begin{array}{c}\mathrm{T} \\
\left({ }^{\circ} \mathrm{C}\right)\end{array}$ & $\begin{array}{c}\sigma_{\max } \\
(\mathrm{MPa})\end{array}$ & $\begin{array}{c}\text { MCRS } \\
(\text { compressive }) \\
(\mathrm{MPa})\end{array}$ \\
\hline 1 & 1 & 1 & 1 & 1 & 150 & 370 & 1295 & -290 \\
2 & 1 & 1 & 2 & 2 & 135 & 350 & 1265 & -302 \\
3 & 1 & 1 & 3 & 3 & 128 & 335 & 1240 & -310 \\
4 & 1 & 2 & 1 & 2 & 133 & 345 & 1252 & -305 \\
5 & 1 & 2 & 2 & 3 & 137 & 320 & 1220 & -320 \\
6 & 1 & 2 & 3 & 1 & 105 & 275 & 1150 & -340 \\
7 & 1 & 3 & 1 & 3 & 124 & 325 & 1225 & -312 \\
8 & 1 & 3 & 2 & 1 & 114 & 302 & 1195 & -324 \\
9 & 1 & 3 & 3 & 2 & 110 & 295 & 1175 & -330 \\
10 & 2 & 1 & 1 & 2 & 172 & 395 & 1315 & -272 \\
11 & 2 & 1 & 2 & 3 & 161 & 372 & 1301 & -286 \\
12 & 2 & 1 & 3 & 1 & 131 & 348 & 1273 & -303 \\
16 & 2 & 2 & 1 & 3 & 139 & 321 & 1278 & -298 \\
14 & 2 & 2 & 2 & 1 & 128 & 345 & 1255 & -308 \\
15 & 2 & 2 & 3 & 2 & 120 & 329 & 1230 & -320 \\
16 & 2 & 3 & 1 & 1 & 134 & 335 & 1235 & -301 \\
17 & 2 & 3 & 2 & 2 & 128 & 325 & 1220 & -314 \\
18 & 2 & 3 & 3 & 3 & 119 & 313 & 1214 & -325 \\
19 & 3 & 1 & 1 & 3 & 183 & 404 & 1330 & -250 \\
20 & 3 & 1 & 2 & 1 & 141 & 365 & 1287 & -277 \\
21 & 3 & 1 & 3 & 2 & 131 & 351 & 1269 & -287 \\
22 & 3 & 2 & 1 & 1 & 163 & 390 & 1175 & -323 \\
23 & 3 & 2 & 2 & 2 & 155 & 380 & 1185 & -315 \\
24 & 3 & 2 & 3 & 3 & 145 & 365 & 1192 & -308 \\
25 & 3 & 3 & 1 & 2 & 150 & 350 & 1275 & -311 \\
26 & 3 & 3 & 2 & 3 & 141 & 335 & 1260 & -320 \\
27 & 3 & 3 & 3 & 1 & 112 & 291 & 1210 & -341 \\
\hline
\end{tabular}

Table 8: Response table for SNR of Cutting Force

\begin{tabular}{lcccc}
\hline Level & $\begin{array}{c}\text { Cutting speed } \\
(\mathrm{m} / \mathrm{min})\end{array}$ & Amplitude $(\mu \mathrm{m})$ & $\begin{array}{c}\text { Frequency } \\
(\mathrm{Hz})\end{array}$ & $\begin{array}{c}\text { Feed rate } \\
(\mathrm{mm} / \mathrm{rev})\end{array}$ \\
\hline 1 & $\mathbf{- 4 1 . 9 7}$ & -43.34 & -43.44 & $\mathbf{- 4 2 . 2 6}$ \\
2 & -42.66 & -42.61 & -42.74 & -42.67 \\
3 & -43.26 & $\mathbf{- 4 1 . 9 5}$ & $\mathbf{- 4 1 . 7 1}$ & -42.97 \\
Delta & 1.29 & 1.39 & 1.73 & 0.71 \\
Rank & 3 & 2 & 1 & 4 \\
Optimum & 1 & 3 & 3 & 1 \\
\hline
\end{tabular}

Table 9: ANOVA table for cutting force $\mathrm{F}_{\mathrm{c}}$ using $\mathrm{SN}$ data

\begin{tabular}{lccccc}
\hline Factors & DOF & SSTR & MSTR & F - Test & \% Contribution (P) \\
\hline Cutting Speed & 2 & 7.496 & 3.7478 & 15.33 & 20.49 \\
Amplitude & 2 & 8.717 & 4.3584 & 17.82 & 23.83 \\
Frequency & 2 & 13.687 & 6.8434 & 27.98 & 37.41 \\
Feed rate & 2 & 2.285 & 1.1427 & 4.67 & 6.24 \\
Error & 18 & 4.402 & 0.2446 & & 12.03 \\
Total & 26 & 36.587 & & & 100.00 \\
\hline
\end{tabular}




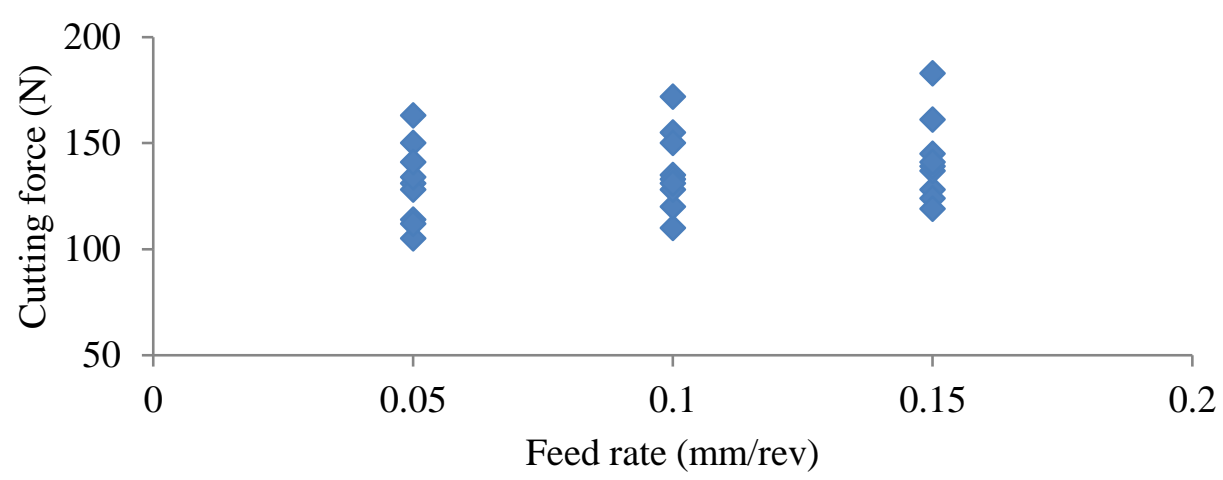

(a)

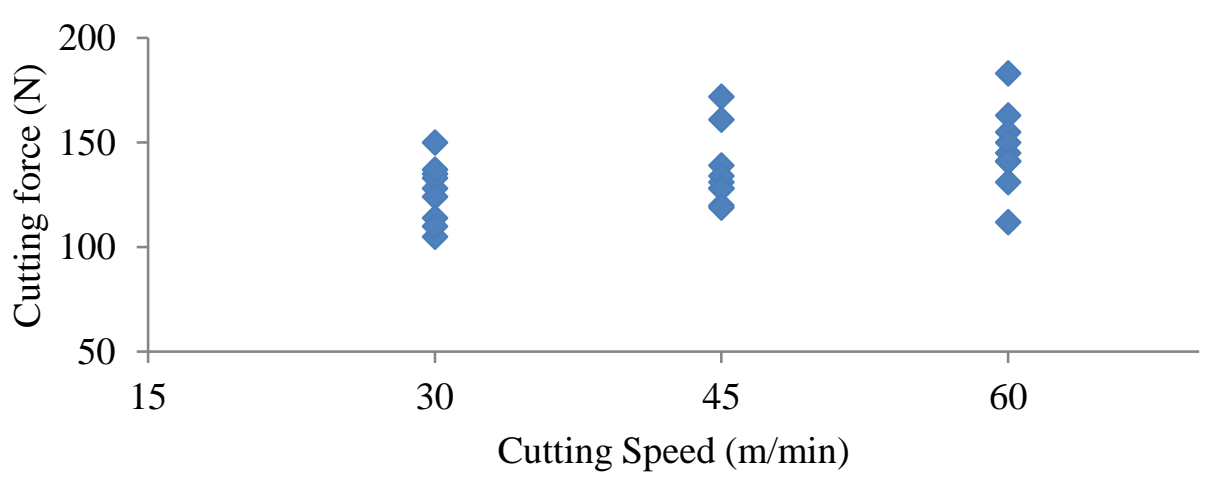

(b)

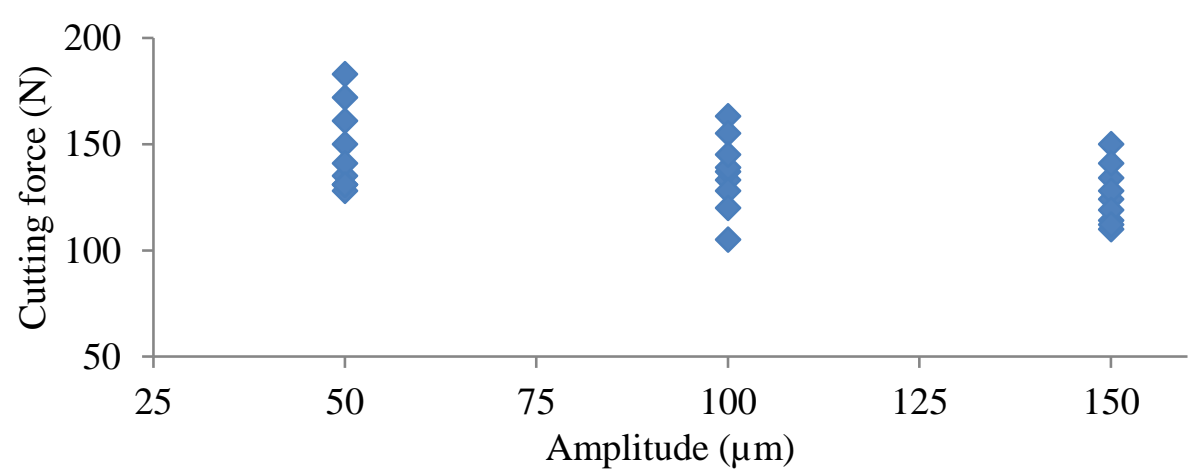

(c)

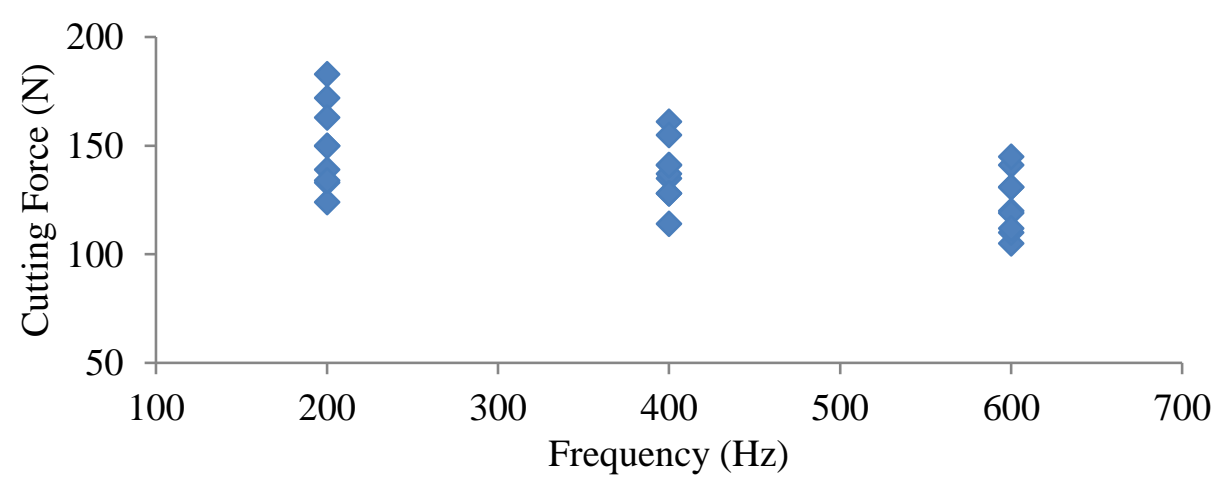

(d)

Figure 4: Variation of cutting force with (a) feed rate, (b) cutting speed, (c) amplitude and; (d) frequency. 


\section{Effect of parameters on cutting temperature}

Table 10 and 11 depict the influence of each parameter on cutting temperature based on response data for SNR and ANOVA. Figure 5 shows the variation of cutting temperature with cutting speed, feed rate, amplitude and frequency. The cutting temperature in the VAT process was affected more by amplitude than other parameters. The increase in cutting speed provides less time span to evacuate heat generated in the cutting zone which results in high temperature. This leads to adiabatic heat conditions in cutting zone. This thermal dominant mechanism got suppressed with lower speeds resulted in lower cutting temperatures. The increase in amplitude and frequency resulted for the decrease in temperature due to more time available between successive cycles in VAT.

Table 10. Response table for SNR of cutting temperature.

\begin{tabular}{lcccc}
\hline Level & $\begin{array}{c}\text { Cutting speed } \\
(\mathrm{m} / \mathrm{min})\end{array}$ & $\begin{array}{c}\text { Amplitude } \\
(\mu \mathrm{m})\end{array}$ & $\begin{array}{c}\text { Frequency } \\
(\mathrm{Hz})\end{array}$ & $\begin{array}{c}\text { Feed rate } \\
(\mathrm{mm} / \mathrm{rev})\end{array}$ \\
\hline 1 & $\mathbf{- 5 0 . 1 8}$ & -51.24 & -51.08 & $\mathbf{- 5 0 . 4 6}$ \\
2 & -50.07 & -50.62 & -50.7 & -50.77 \\
3 & -51.07 & $\mathbf{- 5 0 . 0 6}$ & $\mathbf{- 5 0 . 1 3}$ & -50.69 \\
Delta & 0.89 & 1.18 & 0.95 & 0.31 \\
Rank & 3 & 1 & 2 & 4 \\
Optimum & 1 & 3 & 3 & 1 \\
\hline
\end{tabular}

Table 11. ANOVA table for cutting temperature using SN data.

\begin{tabular}{lccccc}
\hline Factor & DOF & SSTR & MSTR & F - Test & \% contribution $(\mathrm{P})$ \\
\hline Cutting speed & 2 & 3.5486 & 1.7743 & 9.58 & 19.98 \\
Amplitude & 2 & 6.3171 & 3.1586 & 17.06 & 35.57 \\
Frequency & 2 & 4.1165 & 2.0583 & 11.11 & 23.17 \\
Feed rate & 2 & 0.4465 & 0.2233 & 1.21 & 2.51 \\
Error & 18 & 3.3333 & 0.1852 & & 18.77 \\
Total & 26 & 17.7621 & & & 100.00 \\
\hline
\end{tabular}

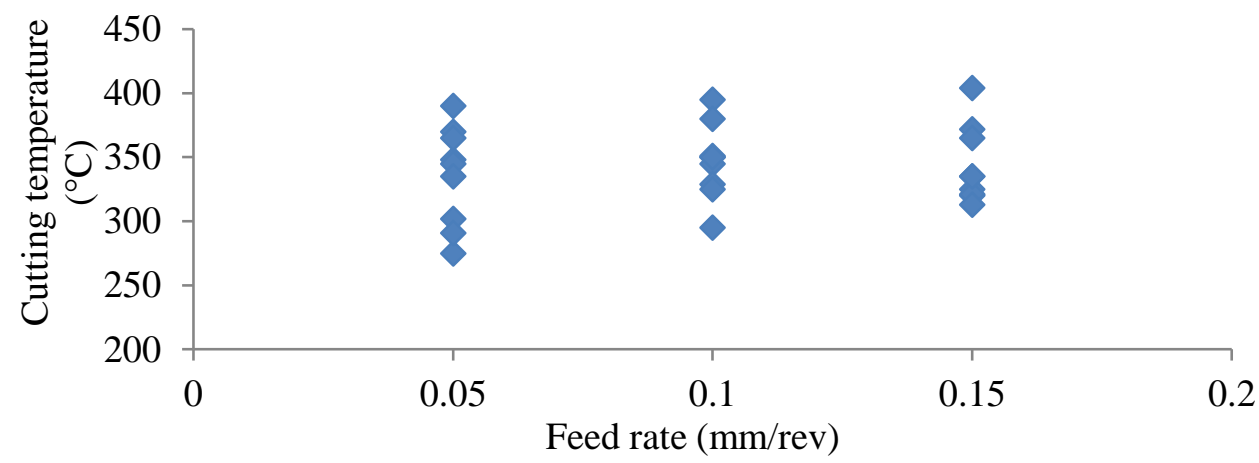

(a) 


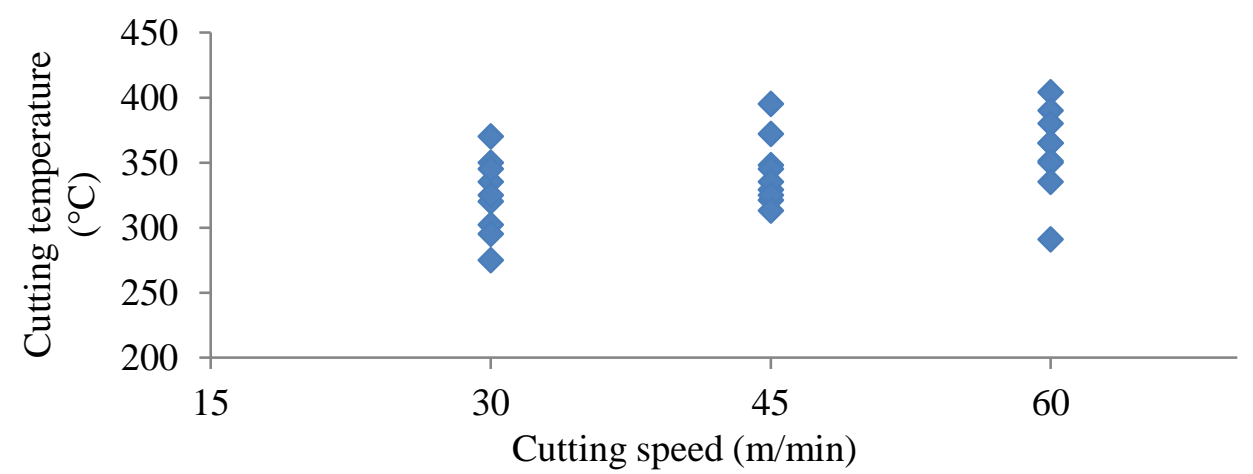

(b)

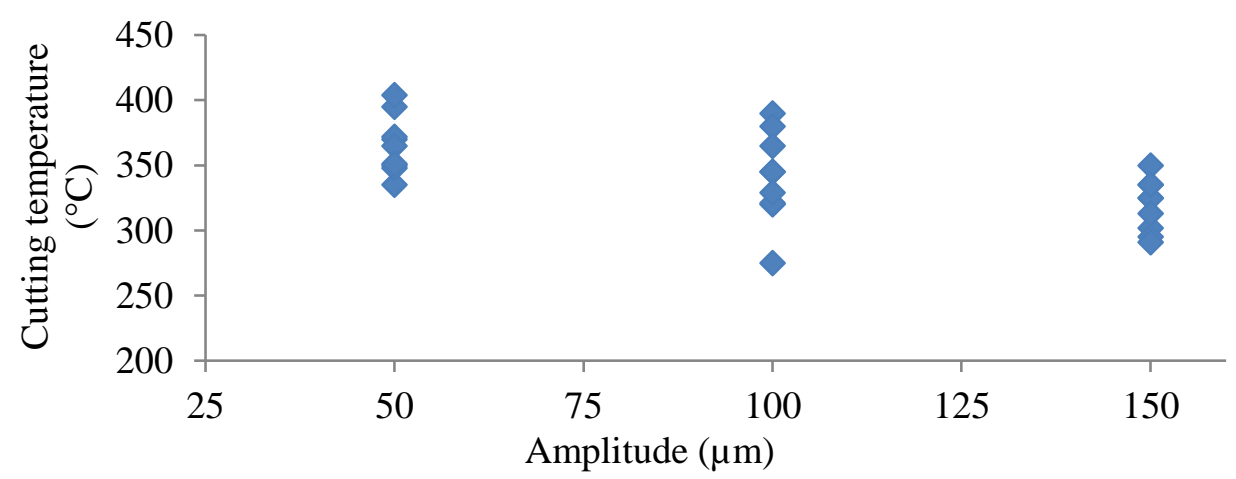

(c)

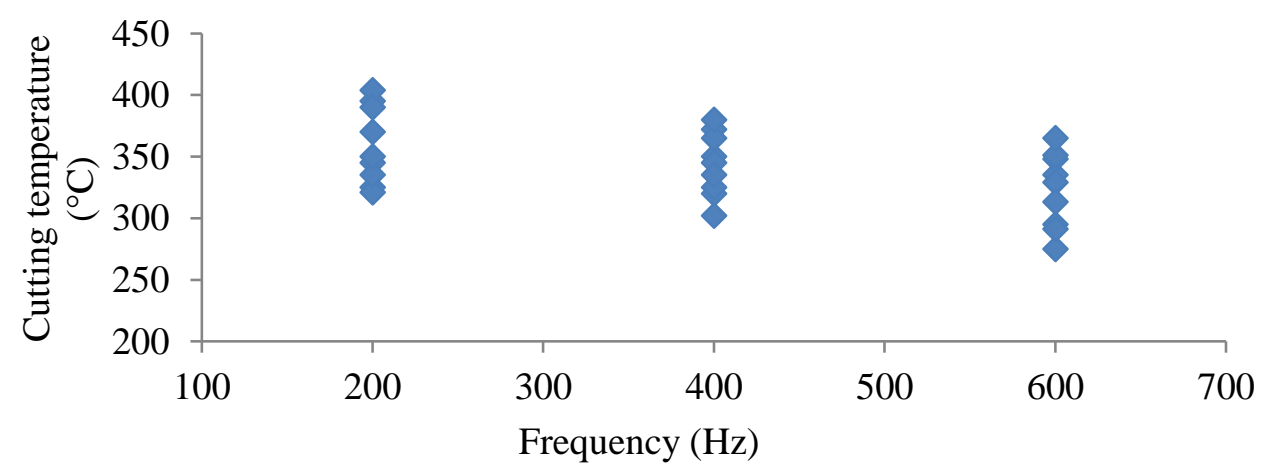

(d)

Figure 5. Variation of cutting temperature with (a) feed rate, (b) cutting speed, (c) amplitude and; (d) frequency.

\section{Effect of parameters on equivalent stress}

Table 12 and 13 show response data for SNR and ANOVA. It is observed that the cutting speed and feed rate have less effect on equivalent stress compared to vibrating parameters. The influence of amplitude is most significant than others on equivalent stresses. Figure 6 shows the variation of equivalent stresses with cutting speed, feed rate, amplitude and frequency. The equivalent stress is increased by cutting speed and feed rate whereas it decreased with increase of amplitude and frequency due to relaxation between tool and workpiece. 
Table 12. Response table for SNR of equivalent stress.

\begin{tabular}{lcccc}
\hline Level & $\begin{array}{c}\text { Cutting speed } \\
(\mathrm{m} / \mathrm{min})\end{array}$ & $\begin{array}{c}\text { Amplitude } \\
(\mu \mathrm{m})\end{array}$ & $\begin{array}{c}\text { Frequency } \\
(\mathrm{Hz})\end{array}$ & $\begin{array}{c}\text { Feed rate } \\
(\mathrm{mm} / \mathrm{rev})\end{array}$ \\
\hline 1 & $\mathbf{- 6 1 . 7 5}$ & -62.18 & -62.03 & $\mathbf{- 6 1 . 8}$ \\
2 & -61.99 & $\mathbf{- 6 1 . 6 9}$ & -61.89 & -61.88 \\
3 & -61.88 & -61.75 & $\mathbf{- 6 1 . 7}$ & -61.94 \\
Delta & 0.24 & 0.5 & 0.33 & 0.15 \\
Rank & 3 & 1 & 2 & 4 \\
Optimum & 1 & 2 & 3 & 1 \\
\hline
\end{tabular}

Table 13. ANOVA table for equivalent stress using SN data.

\begin{tabular}{lccccc}
\hline Factor & DOF & SSTR & MSTR & F- Test & \% contribution (P) \\
\hline Cutting speed & 2 & 0.25664 & 0.12832 & 4.20 & 9.45 \\
Amplitude & 2 & 1.31740 & 0.65870 & 21.58 & 48.52 \\
Frequency & 2 & 0.49493 & 0.24747 & 8.11 & 18.23 \\
Feed rate & 2 & 0.09697 & 0.04848 & 1.59 & 3.57 \\
Error & 18 & 0.54946 & 0.03053 & & 20.23 \\
Total & 26 & 2.71541 & & & 100.00 \\
\hline
\end{tabular}

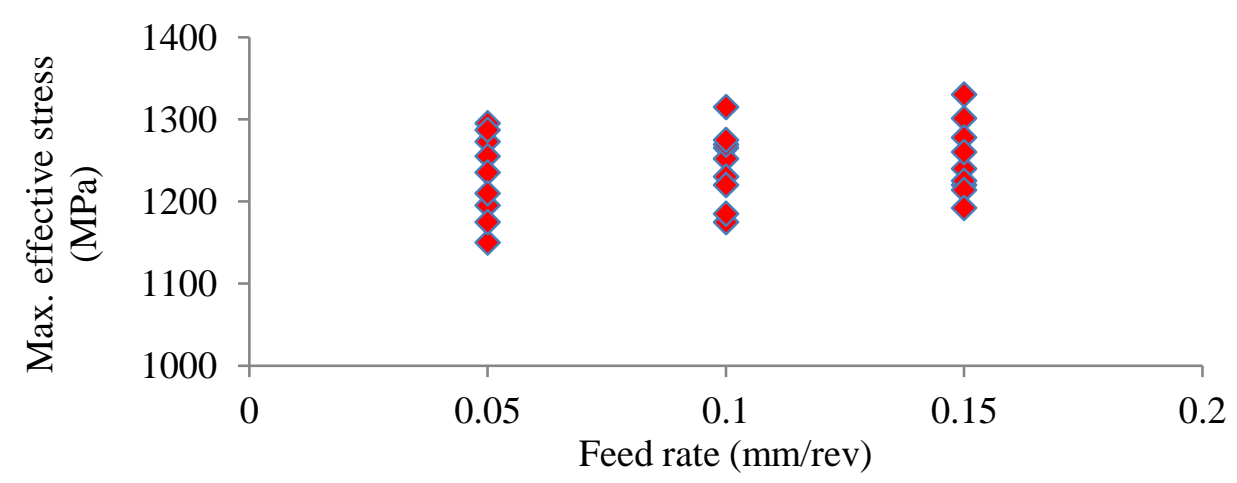

(a)

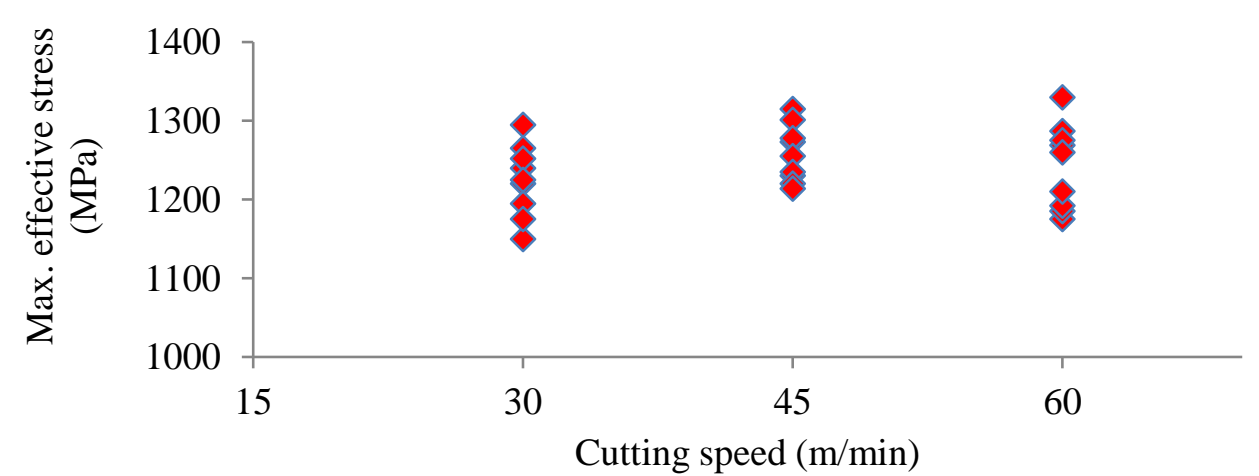

(b) 


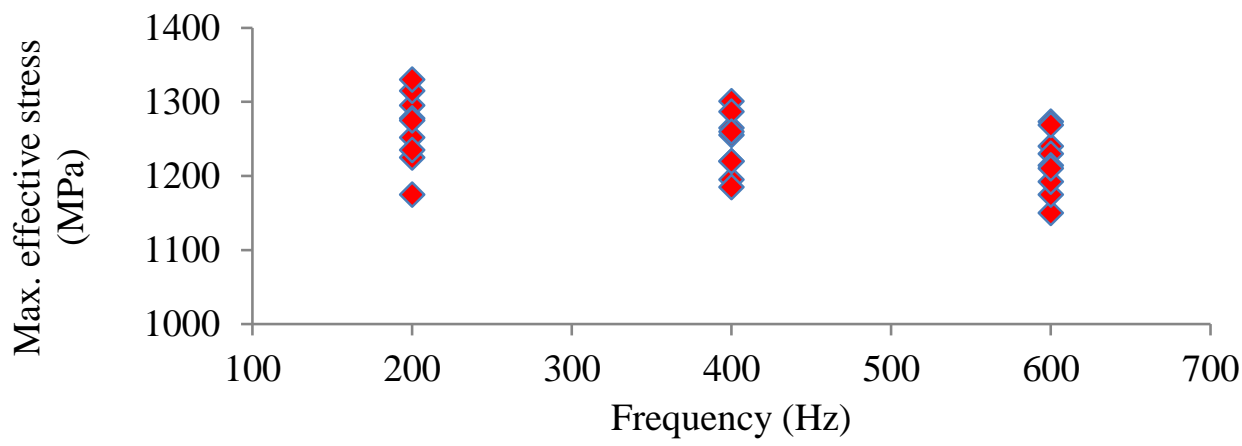

(c)

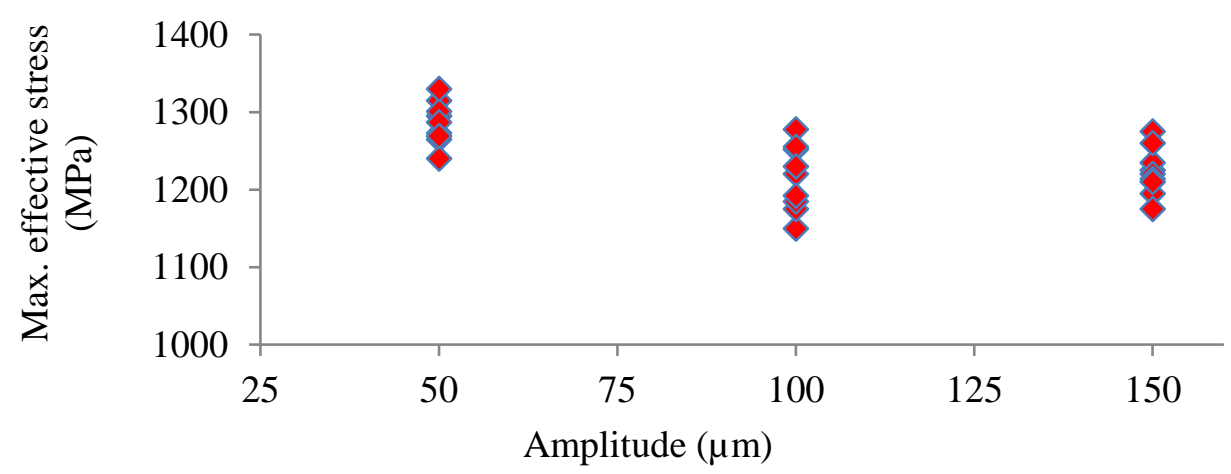

(d)

Figure 6. Variation of equivalent stress with (a) feed rate, (b) cutting speed,

(c) amplitude and; (d) frequency.

\section{Effect of parameters on MCRS (compressive)}

Table 14 and 15 depict the influence of each process parameter on MCRS. The effect of cutting speed and feed rate on MCRS is negligible. The influence of vibrating parameters is more on MCRS. Moreover, the influence of amplitude is more than frequency. Figure 7 shows the variation of MCRS on cutting speed, feed rate, amplitude and frequency. The MCRS is increased by cutting speed and feed rate whereas it decreased with increase in amplitude and frequency due to successive impacts between tool and workpiece regularly.

Table 14. Response table for SNR of MCRS (compressive).

\begin{tabular}{lcccc}
\hline Level & $\begin{array}{c}\text { Cutting speed } \\
(\mathrm{m} / \mathrm{min})\end{array}$ & $\begin{array}{c}\text { Amplitude } \\
(\mu \mathrm{m})\end{array}$ & $\begin{array}{c}\text { Frequency } \\
(\mathrm{Hz})\end{array}$ & $\begin{array}{c}\text { Feed rate } \\
(\mathrm{mm} / \mathrm{rev})\end{array}$ \\
\hline 1 & $\mathbf{4 9 . 9 5}$ & 49.12 & 49.4 & $\mathbf{4 9 . 8 6}$ \\
2 & 49.62 & 49.97 & 49.74 & 49.71 \\
3 & 49.61 & $\mathbf{5 0 . 0 9}$ & $\mathbf{5 0 . 0 4}$ & 49.61 \\
Delta & 0.34 & 0.97 & 0.65 & 0.25 \\
Rank & 3 & 1 & 2 & 4 \\
Optimum & 1 & 3 & 3 & 1 \\
\hline
\end{tabular}

The impact produced by stress wave velocity in VAT has greater influence than cutting velocity. So, the inner stress of chip has reached ultimate strength before cutting tool engaged with the workpiece. Hence, the cutting force required for the material 
removal is lowered in VAT. Moreover, tool-workpiece contact ratio decreased with increase in amplitude and frequency. This leads to decrease in temperature due to aerodynamic lubrication in cutting zone. Hence the chance of tensile residual stresses is suppressed due to favorable thermal conditions.

Table 15. ANOVA table for MCRS using SN data.

\begin{tabular}{lccccc}
\hline Factors & DOF & SSTR & MSTR & F- Test & \% contribution $(\mathrm{P})$ \\
\hline Cutting Speed & 2 & 0.6807 & 0.34037 & 4.09 & 7.27 \\
Amplitude & 2 & 5.0183 & 2.50913 & 30.15 & 53.57 \\
Frequency & 2 & 1.8836 & 0.94178 & 11.32 & 20.11 \\
Feed rate & 2 & 0.2867 & 0.14337 & 1.72 & 3.06 \\
Error & 18 & 1.4979 & 0.08321 & & 15.99 \\
Total & 26 & 9.3672 & & & 100.00 \\
\hline
\end{tabular}

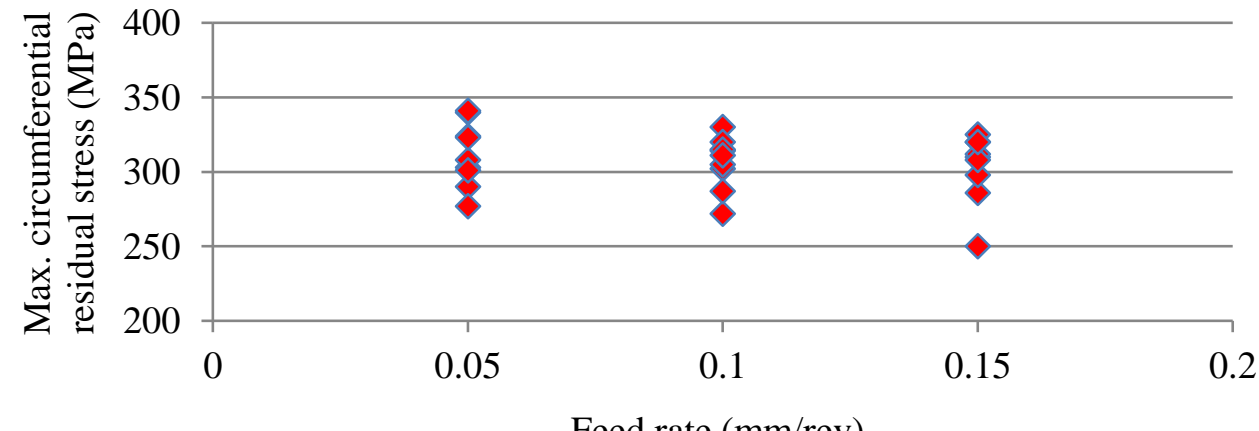

(a)

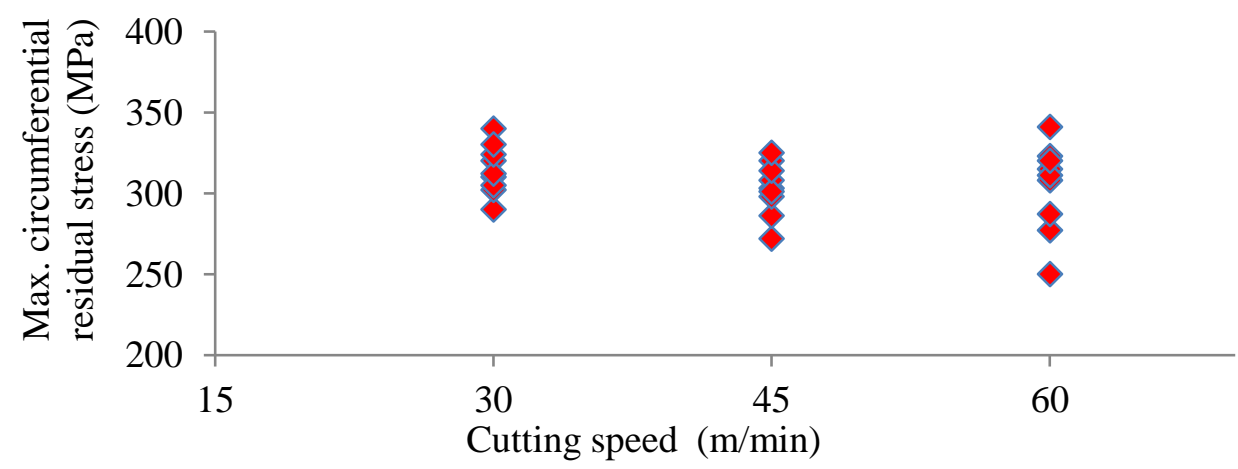

(b)

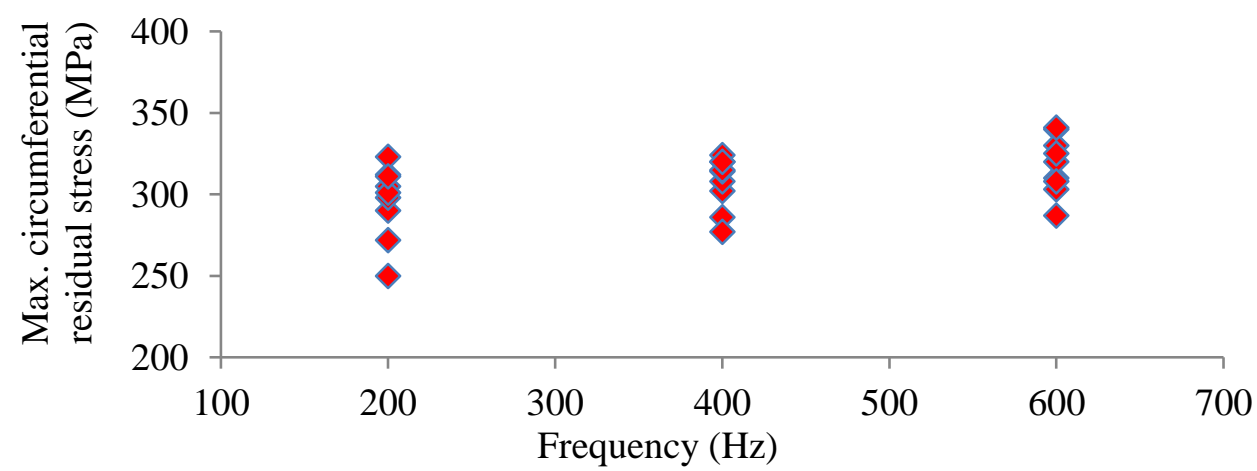

(c) 


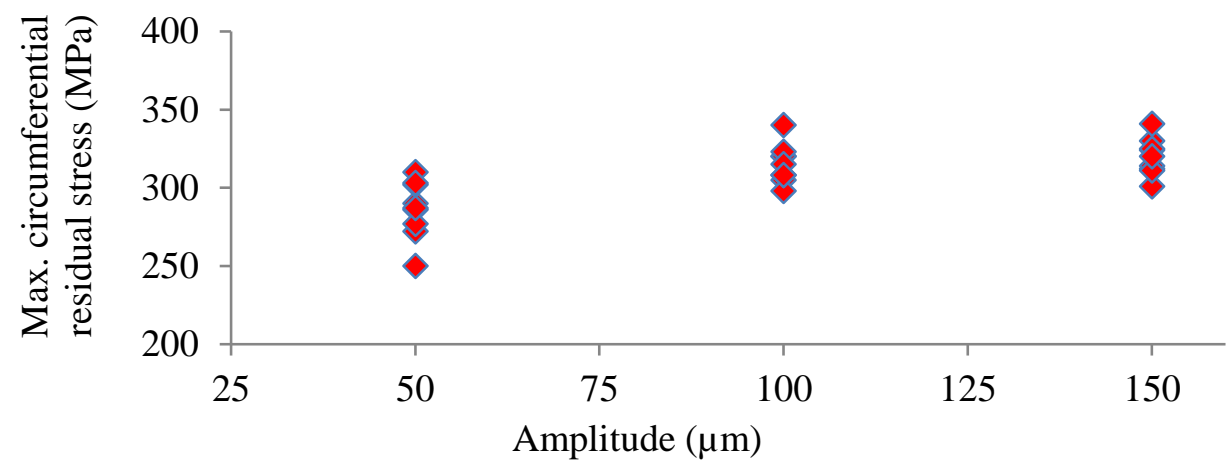

(d)

Figure 7. Variation of MCRS (compressive) with (a) feed rate, (b) cutting speed, (c) amplitude and; (d) frequency.

\section{Optimum Design}

Residual error was calculated statistically from mean values. The residual error of DoF is calculated by subtracting the DoF associated with the factor from the total degrees of freedom. The SSTR is used to quantify the variation between the treatment groups and error sum of squares (SSE) is used to qualify the variation between data. The SSE is calculated from Eq. (4) [22].

$$
\mathrm{SSE}=\left(\mathrm{n}_{1}-1\right) \mathrm{x}_{1}^{2}+\left(\mathrm{n}_{2}-1\right) \mathrm{x}_{2}^{2}+\ldots+\left(\mathrm{n}_{\mathrm{m}}-1\right) \mathrm{x}_{\mathrm{m}}^{2}
$$

where " $\mathrm{m}$ " indicates each individual factor, " $\mathrm{x}$ " indicates variance and " $\mathrm{n}$ " indicates number of observations in the $\mathrm{m}^{\text {th }}$ factor. The optimum levels for cutting speed, feed rate, amplitude and frequency are calculated with the help of response data from $\mathrm{S} / \mathrm{N}$ ratio. The predicted mean of output responses at optimum levels of control parameters is calculated using the Eq. (5). The optimum conditions for all output variables are given in Table 16.

$$
\mathrm{Y}=\overline{\mathrm{Y}}+\left(\overline{\mathrm{A}_{\mathrm{o}}}-\overline{\mathrm{Y}}\right)+\left(\overline{\mathrm{B}_{\mathrm{o}}}-\overline{\mathrm{Y}}\right)+\left(\overline{\mathrm{C}_{\mathrm{o}}}-\overline{\mathrm{Y}}\right)+\left(\overline{\mathrm{D}_{\mathrm{o}}}-\overline{\mathrm{Y}}\right)
$$

where $\bar{Y}$ is the grand mean of output response values from output response table and $\overline{A_{o}}, \overline{B_{o}}, \overline{C_{o}}$ and $\overline{D_{o}}$ are average of output response variable for cutting speed, amplitude, frequency and feed rate at optimum levels. The output responses cutting force, cutting temperature, equivalent stress and MCRS (compressive) are calculated from Eqs. (6) to (9) respectively using Y from Eq. (5). These predicted results are verified through the confirmatory test.

Cutting force, $\mathrm{F}_{\mathrm{c}}=10^{\frac{-\mathrm{Y}}{20}}$

Cutting temperature, $\mathrm{T}=10 \frac{-\mathrm{Y}}{20}$

Equivalent stresses, $\sigma=10 \frac{-Y}{20}$

MCRS (compressive), $\sigma_{R}=10 \frac{Y}{20}$ 


\section{Confirmatory test}

The confirmatory test was conducted through the FE simulation model which have been validated through experimental values. These simulations are done at optimum machining parameters for all output responses. Then the predicted values from Eq. (5) to (9) are compared with simulated values as shown in Table 17. The optimum input parameters obtained from ANOVA for cutting force, cutting temperature, equivalent stress and MCRS (compressive) are given in Table 16.

Table 16. Optimum input parameters for output responses

\begin{tabular}{lcccc}
\hline & \multicolumn{4}{c}{ Optimum level } \\
\cline { 2 - 5 } Parameter & $\begin{array}{c}\text { Cutting force } \\
(\mathrm{N})\end{array}$ & $\begin{array}{c}\text { Temperature } \\
\left({ }^{\circ} \mathrm{C}\right)\end{array}$ & $\begin{array}{c}\text { Effective stress } \\
(\mathrm{MPa})\end{array}$ & $\begin{array}{c}\text { MCRS } \\
(\text { compressive }) \\
(\mathrm{MPa})\end{array}$ \\
\hline $\begin{array}{l}\text { Feed rate, } \mathrm{D} \\
(\mathrm{mm} / \mathrm{rev})\end{array}$ & 0.05 & 0.05 & 0.05 & 0.05 \\
$\begin{array}{l}\text { Cutting speed, } \\
\text { A (m/min) } \\
\text { Amplitude, } \mathrm{C}\end{array}$ & 30 & 30 & 30 & 30 \\
$(\mu)$ & 150 & 150 & 100 & 150 \\
$\begin{array}{l}\text { Frequency, B } \\
(\mathrm{Hz})\end{array}$ & 600 & 600 & 600 & 600 \\
\hline
\end{tabular}

Table 17. Predicted and simulated results.

\begin{tabular}{lccc}
\hline Parameter & $\begin{array}{c}\text { Predicted } \\
\text { value }\end{array}$ & $\begin{array}{c}\text { Simulated } \\
\text { value }\end{array}$ & \% error \\
\hline Average cutting force & 95.2 & 87.2 & 8.4 \\
Average cutting temperature & 284 & 257.2 & 9.4 \\
Max. equivalent stress & 1161.5 & 1102.03 & 5.1 \\
MCRS (compressive) & 322.3 & 294.2 & 8.7 \\
\hline
\end{tabular}

\section{Grey Relational Analysis}

Grey relational analysis (GRA) ws used for optimum process parameters for multiresponse characteristics. Grey relational coefficients are calculated by normalizing all the responses by giving equal weight of 0.25 for each response. The Grey grades are obtained by averaging Grey relational coefficients of selected response as Grey relational generation [22]. Thus, the multi-object problem is converted into an equivalent single object problem by integrating Taguchi method and GRA. The simulation data obtained for the cutting force, cutting temperature, equivalent stress is normalized based on smaller the best criteria using Eq. (10) whereas MCRS (compressive) is normalized based on larger the best criteria using Eq. (11).

$$
\left[Z_{i j}=\frac{\max \left(y_{i j}, i=1,2, \ldots \ldots . . n\right)-y_{i j}}{\max \left(y_{i j}, i=1,2, \ldots \ldots . . n\right)-\min \left(y_{i j}, i=1,2, \ldots \ldots . n\right)}\right]
$$




$$
\left[Z_{i j}=\frac{y_{i j}-\min \left(y_{i j}, i=1,2, \ldots \ldots . . n\right)}{\max \left(y_{i j}, i=1,2, \ldots \ldots . . n\right)-\min \left(y_{i j}, i=1,2, \ldots \ldots . n\right)}\right]
$$

The normalized values, Grey relational coefficients and Grey grades for each response are presented in Table 18. For identifying the optimum process conditions SNR is determined and ANOVA is employed to know the significant process parameters for each output response.

Table 18. Normalized values, grey relational coefficients and grey grades of responses.

\begin{tabular}{|c|c|c|c|c|c|c|c|c|c|}
\hline \multirow{2}{*}{$\begin{array}{l}\text { Trail } \\
\text { No. }\end{array}$} & \multicolumn{4}{|c|}{ Normalized values } & \multicolumn{4}{|c|}{ Grey relational coefficient } & \multirow{2}{*}{$\begin{array}{l}\text { Grey } \\
\text { grade }\end{array}$} \\
\hline & $\mathrm{F}_{\mathrm{c}}$ & $\mathrm{T}$ & $\sigma_{\max }$ & MCRS & $\mathrm{F}_{\mathrm{c}}$ & $\mathrm{T}$ & $\sigma_{\max }$ & MCRS & \\
\hline 1 & 0.4231 & 0.2636 & 0.1944 & 0.4396 & 0.4643 & 0.4044 & 0.3830 & 0.4643 & 0.4514 \\
\hline 2 & 0.6154 & 0.4186 & 0.3611 & 0.5714 & 0.5652 & 0.4624 & 0.4390 & 0.5652 & 0.4882 \\
\hline 3 & 0.7051 & 0.5349 & 0.5000 & 0.6593 & 0.6290 & 0.5181 & 0.5000 & 0.6290 & 0.5296 \\
\hline 4 & 0.6410 & 0.4574 & 0.4333 & 0.6044 & 0.5821 & 0.4796 & 0.4688 & 0.5821 & 0.5075 \\
\hline 5 & 0.5897 & 0.6512 & 0.6111 & 0.7692 & 0.5493 & 0.5890 & 0.5625 & 0.5493 & 0.5636 \\
\hline 6 & 1.0000 & 1.0000 & 1.0000 & 0.9890 & 1.0000 & 1.0000 & 1.0000 & 1.0000 & 0.8748 \\
\hline 7 & 0.7564 & 0.6124 & 0.5833 & 0.6813 & 0.6724 & 0.5633 & 0.5455 & 0.6724 & 0.5656 \\
\hline 8 & 0.8846 & 0.7907 & 0.7500 & 0.8132 & 0.8125 & 0.7049 & 0.6667 & 0.8125 & 0.6561 \\
\hline 9 & 0.9359 & 0.8450 & 0.8611 & 0.8791 & 0.8864 & 0.7633 & 0.7826 & 0.8864 & 0.7203 \\
\hline 10 & 0.1410 & 0.0698 & 0.0833 & 0.2418 & 0.3679 & 0.3496 & 0.3529 & 0.3679 & 0.4512 \\
\hline 11 & 0.2821 & 0.2481 & 0.1611 & 0.3956 & 0.4105 & 0.3994 & 0.3734 & 0.4105 & 0.4602 \\
\hline 12 & 0.6667 & 0.4341 & 0.3167 & 0.5824 & 0.6000 & 0.4691 & 0.4225 & 0.6000 & 0.5223 \\
\hline 13 & 0.5641 & 0.6434 & 0.2889 & 0.5275 & 0.5342 & 0.5837 & 0.4128 & 0.5342 & 0.5207 \\
\hline 14 & 0.7051 & 0.4574 & 0.4167 & 0.6374 & 0.6290 & 0.4796 & 0.4615 & 0.6290 & 0.5211 \\
\hline 15 & 0.8077 & 0.5814 & 0.5556 & 0.7692 & 0.7222 & 0.5443 & 0.5294 & 0.7222 & 0.5801 \\
\hline 16 & 0.6282 & 0.5349 & 0.5278 & 0.5604 & 0.5735 & 0.5181 & 0.5143 & 0.5735 & 0.5437 \\
\hline 17 & 0.7051 & 0.6124 & 0.6111 & 0.7033 & 0.6290 & 0.5633 & 0.5625 & 0.6290 & 0.5862 \\
\hline 18 & 0.8205 & 0.7054 & 0.6444 & 0.8242 & 0.7358 & 0.6293 & 0.5844 & 0.7358 & 0.6392 \\
\hline 19 & 0.0000 & 0.0000 & 0.0000 & 0.0000 & 0.3333 & 0.3333 & 0.3333 & 0.3333 & 0.4667 \\
\hline 20 & 0.5385 & 0.3023 & 0.2389 & 0.2967 & 0.5200 & 0.4175 & 0.3965 & 0.5200 & 0.4996 \\
\hline 21 & 0.6667 & 0.4109 & 0.3389 & 0.4066 & 0.6000 & 0.4591 & 0.4306 & 0.6000 & 0.5336 \\
\hline 22 & 0.2564 & 0.1085 & 0.8611 & 0.8022 & 0.4021 & 0.3593 & 0.7826 & 0.4021 & 0.5188 \\
\hline 23 & 0.3590 & 0.1860 & 0.8056 & 0.7143 & 0.4382 & 0.3805 & 0.7200 & 0.4382 & 0.5024 \\
\hline 24 & 0.4872 & 0.3023 & 0.7667 & 0.6374 & 0.4937 & 0.4175 & 0.6818 & 0.4937 & 0.5120 \\
\hline 25 & 0.4231 & 0.4186 & 0.3056 & 0.6703 & 0.4643 & 0.4624 & 0.4186 & 0.4643 & 0.5272 \\
\hline 26 & 0.5385 & 0.5349 & 0.3889 & 0.7692 & 0.5200 & 0.5181 & 0.4500 & 0.5200 & 0.5553 \\
\hline 27 & 0.9103 & 0.8760 & 0.6667 & 1.0000 & 0.8478 & 0.8012 & 0.6000 & 0.8478 & 0.7462 \\
\hline
\end{tabular}

The results of response data for SNR and ANOVA for mean Grey grades are presented in Table 19 and 20 respectively. The percentage contribution of each machining parameter on performance characteristic is depicted in Table 20. The vibrating parameters amplitude $(29.88 \%)$ and frequency $(30.01 \%)$ has a major effect on multi-response characteristics compared to feed $(7.11 \%)$ and cutting speed $(8.03 \%)$. It is observed that the optimum level of process parameters for multiresponse are $30 \mathrm{~m} / \mathrm{min}$ of cutting speed, $150 \mu \mathrm{m}$ of amplitude, $600 \mathrm{~Hz}$ of frequency and $0.05 \mathrm{~mm} / \mathrm{rev}$ of feed rate. 
Table 19. Response table for means of grey relational grades.

\begin{tabular}{lcccc}
\hline Level & $\begin{array}{c}\text { Cutting speed } \\
(\mathrm{m} / \mathrm{min})\end{array}$ & $\begin{array}{c}\text { Amplitude } \\
(\mu \mathrm{m})\end{array}$ & $\begin{array}{c}\text { Frequency } \\
(\mathrm{Hz})\end{array}$ & $\begin{array}{c}\text { Feed rate } \\
(\mathrm{mm} / \mathrm{rev})\end{array}$ \\
\hline 1 & $\mathbf{0 . 5 9 5 2}$ & 0.4892 & 0.5059 & $\mathbf{0 . 5 9 2 7}$ \\
2 & 0.5361 & 0.5668 & 0.5370 & 0.5441 \\
3 & 0.5402 & $\mathbf{0 . 6 1 5 5}$ & $\mathbf{0 . 6 2 8 7}$ & 0.5348 \\
Delta & 0.0592 & 0.1263 & 0.1228 & 0.0579 \\
Rank & 3 & 2 & 1 & 4 \\
Optimum & 1 & 3 & 3 & 1 \\
\hline
\end{tabular}

Table 20. ANOVA results for grey grade.

\begin{tabular}{lccccc}
\hline Factors & DOF & SSTR & MSTR & F- Test & \% contribution $(\mathrm{P})$ \\
\hline Cutting Speed & 2 & 0.01964 & 0.009818 & 2.89 & 8.03 \\
Amplitude & 2 & 0.07307 & 0.036533 & 10.77 & 29.88 \\
Frequency & 2 & 0.07338 & 0.036691 & 10.82 & 30.01 \\
Feed rate & 2 & 0.01740 & 0.008700 & 2.57 & 7.11 \\
Error & 18 & 0.06105 & 0.003392 & & 24.97 \\
Total & 26 & 0.24453 & & & 100.00 \\
\hline
\end{tabular}

\section{CONCLUSION}

A 3D FE modelling of orthogonal VAT process for Ti6Al4V alloy was developed in ABAQUS. The model was validated with experimental results from literature at similar conditions. Taguchi technique was used to optimize VAT process. The significant and optimum machining parameters are determined from SNR and ANOVA for cutting force, cutting temperature, equivalent stress and MCRS (compressive). Finally, optimum combinations of control parameters are identified from GRA for all output responses. From this study, following conclusions are drawn.

i. Cutting force, cutting temperature, equivalent stress and MCRS (compressive) developed in the VAT process are less when compared to the CT. The vibro impact between the tool and the workpiece gives a better result in machining of Ti6AL4V when compared to continuous motion in CT.

ii. The influence of vibrating parameters i.e. frequency and amplitude are more on output responses in the VAT process. ANOVA at 95\% confidence level, gives the frequency as the most significant in cutting force while amplitude is the most significant for cutting temperature, equivalent stresses and MCRS (compressive).

iii. The optimum condition was obtained at $30 \mathrm{~m} / \mathrm{min}$ of cutting speed, $150 \mu \mathrm{m}$ of amplitude, $600 \mathrm{~Hz}$ of frequency and $0.05 \mathrm{~mm} / \mathrm{rev}$ of feed rate for cutting force, cutting temperature and MCRS (compressive) while the optimum condition for equivalent stress is $30 \mathrm{~m} / \mathrm{min}$ of cutting speed, $100 \mu \mathrm{m}$ of amplitude, $600 \mathrm{~Hz}$ of frequency and $0.05 \mathrm{~mm} / \mathrm{rev}$ of feed rate.

iv. The Taguchi based grey relational analysis indicates that the optimum condition for all output responses is $30 \mathrm{~m} / \mathrm{min}$ of cutting speed, $150 \mu \mathrm{m}$ of amplitude, 600 $\mathrm{Hz}$ of frequency and $0.05 \mathrm{~mm} / \mathrm{rev}$ of feed rate. Amplitude and frequency have a greater influence on multiple performance characteristics than speed and feed rate. 


\section{REFERENCES}

[1] Brehl DE, Dow TA. Review of vibration-assisted machining.Precision Engineering. 2008;32:153-172.

[2] Thoe TB, Aspin Wall DK, Wise MLH. Review on ultrasonic machining. International Journal of Machine Tools Manufacture. 1998;38:239-255.

[3] Silberschmidt VV, Mahdy MA, Gouda MA, Naseer A, Maurotto A, Roy A. Surface-roughness improvement in ultrasonically assisted turning. Procedia CIRP. 2014:13:49-54.

[4] Nestler A, Schubert A. Surface properties in ultrasonic vibration assisted turning of particle reinforced aluminium matrix composites. Procedia CIRP. 2014; 13: 125-130.

[5] Ahmed N, Mitrofanov AV, Babitsky VI, Silberschmidt VV. Analysis of material response to ultrasonic vibration loading in turning Inconel 718. Material Science and Engineering:A. 2006;424;318-325.

[6] Mitrofanov AV, Babitsky VI, Silberschmidt VV. Finite element analysis of ultrasonically assisted turning of Inconel 718. Journal of Materials Processing Technology. 2004;153-154:233-239.

[7] Ahmed N, Mitrofanov AV, Babitsky VI, Silberschmidt VV. Analysis of forces in ultrasonically assisted turning. Journal of Sound and Vibration. 2007;308;845854.

[8] Nath C, Rahman M. Effect of machining parameters in ultrasonic vibration cutting. International Journal of Machine Tools \& Manufacture. 2008;48:965974.

[9] Amini S, Soleimanimehr H, Nategh MJ, Abudollah A, Sadeghi MH. FEM analysis of ultrasonic-vibration-assisted turning and the vibratory tool. Journal of materials processing technology. 2008; 201:43-47.

[10] Ahmed Syed A, Sathyan S. Experimental investigation of transverse vibrationassisted orthogonal cutting of AL-2024. International Journal of Machine Tools \& Manufacture. 2010; 50: 294-302.

[11] Babitsky VI, Kalashnikov AN, Meadows A,Wijesundara AAHP. Ultrasonically assisted turning of aviation materials. Journal of Materials Processing Technology. 2003;132:157-167.

[12] Mondelin A, Valiorgue F, Rech J, Coret M, Feulvarch E. Hybrid model for the prediction of residual stresses induced by $15-5 \mathrm{PH}$ steel turning.International journal of Mechanical science. 2012; 58: 69-85.

[13] Xueping Z,Erwei G, Richard Liu C. Optimization of process parameter of residual stresses for hard turned surfaces. Journal of Materials Processing Technology. 2009;209:4286-4291.

[14] Saini S, Ahuja IS, Sharma VS. Residual stresses, surface roughness, and tool wear in hard turning: a comprehensive review. Materials and Manufacturing Processes. 2012; 27:583-598.

[15] $\mathrm{Fu}$ WE, Cohen PH, Ruud CO. Experimental investigation of the machining induced residual stress tensor under mechanical loading. Journal of Manufacturing Processes. 2009;11: 88-96.

[16] Capello E. Residual stresses in turning Part I: influence of process parameters. Material Processing Technology. 2005;160: 221-228.

[17] Rech J, Moisan A. Surface integrity in finish hard turning of case-hardened steels. International Journal of Machine Tools \& Manufacture. 2003:43: 543-550.. 
[18] Ulutan D, Erdem Alaca B, Lazoglu I. Analytical modelling of residual stresses in machining. Journal of Materials Processing Technology. 2007;183:77-87.

[19] Saini S, Ahuja IS ,Sharma VS. Modelling the effects of cutting parameters on residual stresses in hard turning of AISI H11 tool steel. International journal of advanced manufacturing technology. 2013;65: 667-678.

[20] Naresh KM, Vamsi KP, Xiaoliang J. Assessment of high and low frequency vibration assisted turning with material hardness. International Journal of Machining and Machinability of Materials. 2017;19: 110-135.

[21] Özel T, Ulutan D. Prediction of machining induced residual stresses in turning of titanium and nickel based alloys with experiments and finite element simulations. CIRP Annals - Manufacturing Technology. 2012;61:547-550.

[22] Ross PJ. Taguchi Techniques for Quality Engineering.McGraw- Hill, New York; 1988.

[23] Sharma V, Pandey PM. Optimization of machining and vibration parameters for residual stresses minimization in ultrasonic assisted turning of 4340 hardened steel. Ultrasonics. 2016 ; 60: 172-182.

[24] Patricia ME, Shreyes M, Kai L. Influence of the stress, strain, and temperature on the surface roughness of an AISI 52100 steel dueto an orthogonal cut. Journal of Material Engineering and Performance. 2005;14: 582-590.

[25] Emre YC, Mustafa G. Modelling and optimization of the cutting conditions in hard turning of high-alloy white cast iron (Ni-Hard). Proceedings Of The Institution Of Mechanical Engineers, Part C: Journal Of Mechanical Engineering Science. 2012;227:2280-2290.

[26] Irfan U, Kubilay A. Numerical simulation of orthogonal machining process using multilayer and single-layer coated tools. International journal of advanced manufacturing technology. 2011;54:889-910.

[27] Gary WO, University of Minnesota. A First Course in Design and Analysis of Experiments. 2010;ISBN 0-7167-3510-5.

[28] Stephanie F, Mike O, Ben T, John Z. Design of experiments Via Taguchi methods: Orthogonal Arrays. https://controls.engin.umich.edu/wiki/index.php/Design of experiments via taguchi methods: orthogonal arrays; 2007.

[29] Johnson GR and Cook WH. A constitutive model and data for metals subjected to large strains, high strain rates, and high temperatures.Proceedings, 7th International Symposium on Ballistics, April, Hague, Netherlands; 1983.

[30] Patil S, Joshi S, Tewari A, Joshi SS. Modelling and simulation of effect of ultrasonic vibrations on machining of Ti-6Al-4V. Ultrasonics. 2014;54:694-705.

[31] Johnson GR, Cook WH. Fracture characteristics of three metals subjected to various strains, strain rates, temperatures and pressures. Engineering Fracture Mechanics. 1985;21:31-48. 